Title: Student engagement with teacher and automated feedback on L2 writing Author details:

Zhe (Victor) Zhang, victorzz@hku.hk , +85239177337, Rm 650, Run Run Shaw Tower, Centennial Campus, The University of Hong Kong, Hong Kong

Ken Hyland, khyland@hku.hk, Rm 648, Run Run Shaw Tower, Centennial Campus, The University of Hong Kong, Hong Kong 
Zhe (Victor) Zhang is a PhD candidate in the Centre for Applied English Studies (CAES) at the University of Hong Kong. His research area includes ESL/EFL writing, second language acquisition, and educational assessment. His publications have appeared in ELT Journal and Asian Journal of Applied Linguistics. Email: victorzz@hku.hk

Ken Hyland is a Chair Professor of Applied Linguistics and Director of the Centre for Applied English Studies at the University of Hong Kong. He has published over 200 articles and 26 books on language education and academic writing. He was founding co-editor of the Journal of English for Academic Purposes and was co-editor of Applied Linguistics. Email: khyland@hku.hk 
- This case study explored two L2 students' engagement with teacher and AWE feedback on L2 writing.

- Affective, behavioral, and cognitive (ABC) engagement with feedback were analyzed.

- The highly engaged learner outperformed the moderately engaged learner.

- Student engagement is a key factor in the success of formative assessment in L2 writing. 


\title{
Student engagement with teacher and automated feedback on L2 writing
}

\begin{abstract}
Research on feedback in second language writing has grown enormously in the past 20 years and has expanded to include studies comparing human raters and automated writing evaluation (AWE) programs. However, we know little about the ways students engage with these different sources of feedback or their relative impact on writing over time. This naturalistic case study addresses this gap, looking at how two Chinese students of English engage with both teacher and AWE feedback on their writing over a 16-week semester. Drawing on student texts, teacher feedback, AWE feedback, and student interviews, we identify the strengths and weaknesses of both types of feedback and show how engagement is a crucial mediating variable in the use students make of feedback and the impact it has on their writing development. We argue that engagement is a key factor in the success of formative assessment in teaching contexts where multiple drafting is employed. Our results show that different sources of formative assessment have great potential in facilitating student involvement in writing tasks and we highlight some of these pedagogical implications for promoting student engagement with teacher and AWE feedback.
\end{abstract}

\section{Introduction}

Feedback on second language writing is widely acknowledged to offer considerable learning benefits, providing writers with a sense of audience and an understanding what readers' value in a text (Goldstein, 2005; K. Hyland, 2016). Equally however, research reminds us that it does not always fulfill this potential (e.g. Ferris, 2006; Truscott \& Hsu, 2008) and surveys reveal 
significant student dissatisfaction (Carless, 2006). A great deal of this research, however, has focused on error correction and limited itself to particular modes of delivery, examining the effectiveness of teacher written feedback (Ferris, 1997), oral conferencing (Weissberg, 2006), peer feedback (Mendonca \& Johnson, 1994) or machine marking (Warschauer \& Ware, 2006). The assumption underlying much of this research is that feedback can improve L2 students' writing abilities and consolidate language learning if delivered effectively rather than if it is received attentively. But the mere provision of feedback does not automatically lead to writing improvement. Rather, it is the effective student engagement with this response to their work that is likely to unlock the benefits of feedback.

Student engagement with feedback, however, has been an under-researched area in L2 writing, although it has been shown to play a pivotal role in learning in studies of evaluation in higher education (Handley, Price \& Millar, 2011; Price, Handley \& Millar, 2011). Against such a background, this study aims to explore the construct of student engagement with feedback in L2 writing looking at two key delivery methods: teacher written feedback and computer-generated feedback or Automated Writing Evaluation (AWE). We look at how two Chinese students of English engage with both teacher feedback and AWE feedback on their writing over a 16-week semester in a Chinese university. We suggest that student engagement is a key factor in the success of writing development and how these different sources of feedback have great potential in facilitating L2 students' involvement in their writing.

\section{The construct of student engagement}

Broadly, engagement refers to the extent students are invested or committed to their learning, embracing a complex of factors which can be seen in students' responses to texts and 
their attitudes to writing and responding. It is an umbrella term which brings together students' degree of attention, curiosity, interest and willingness to employ their language proficiency and a repertoire of learning skills to make progress. These are realised through affective, behavioral and cognitive elements which can help facilitate effective responses to feedback. Engagement has traditionally been discussed in relation to students' sense of belonging at school and their academic performance, but there is some evidence linking student engagement with positive academic outcomes (Fredricks, 2013; Skinner \& Pitzer, 2012). It is equally possible, however, that students who have good academic results may be disengaged from learning tasks and school activities (Willms, 2003; Zyngier, 2008). The lack of consensus over the definition of student engagement lies behind these inconsistent findings.

Finn (1989) proposed a model of student engagement which includes participation, or the behavioral component that contains students' compliance with school rules, response to teacher directions, and completion of assigned work, and identification, an affective component which concerns a sense of belonging and feelings toward school and learning. However, Student engagement may be more complicated than observable behaviors and emotions because students may be observed being on task without deeply processing the learning content (Appleton, Christenson, Kim, \& Reschly, 2006).

More helpful is Fredricks, Blumenfeld, and Paris (2004) conceptualization of student engagement as encompassing three interrelated dimensions: behavioural, emotional, and cognitive. Behavioural engagement refers to positive conduct in class and at school, involvement in academic tasks, and participation in school activities. Emotional engagement includes students' affective reactions in the classroom and at school such as happiness, sadness, boredom, anxiety, and interest. Cognitive engagement is concerned with psychological 
investment in learning and strategic learning. The three dimensions of engagement are dynamically interconnected, bound together as both cognition and emotions influence human behaviors (Pessoa, 2008). These concepts also overlap with constructs investigated by other researchers. For example, student interest, attitudes, values are examined in the research of emotional engagement (Fredricks \& McColskey, 2012), and studies on cognitive engagement are associated with the exploration of constructs such as motivation and self-regulated learning (Boekaerts, Pintrich, \& Zeider, 1999; Perry, Turner, \& Meyer, 2006).

In addition to the difficulties of conceptualizing student engagement is how to measure it. Behavioral engagement is normally subdivided into positive behaviors, effort, attention and other participatory behaviors at school, and has been measured through teacher report and observation (Stipek, 2002). Emotional engagement is often operationalized as identification with school (Voelkl, 1997) and various emotions related to school work, teachers, and peers (Skinner \& Belmont, 1993). Measurement of emotional engagement has been conducted via student selfreport and observation (Finn, 1989; Skinner, Kindermann, \& Furrer, 2009). Things become more complicated when measuring cognitive engagement as it is not readily observable so most research has relied on survey items and self-report questionnaires to measure strategy use, volitional control, and psychological investment (Gamoran \& Nystrand, 1992)

In summary, while open to multiple interpretations and beset by difficulties of measurement, student engagement is generally believed to correlate positively with academic achievement and has great potential to improve students' school outcomes. Encouraging is the fact that student engagement is malleable and can be affected by teachers and parents, and shaped by wider teaching practices and school policies (Fredricks et al., 2004; Willms, 2003). 


\section{Student engagement with feedback in L2 writing}

A number of studies have suggested that student engagement with written corrective feedback facilitates language acquisition and writing development. In their study of two L2 writers' engagement with teacher feedback given as reformulations, for example, Qi and Lapkin (2001) argue that the quality of noticing, related to the depth of processing feedback, is a key factor in improvement in students' revisions. Engagement also seems to involve students in devoting cognitive resources to understanding or memorizing the feedback they are given (Sachs \& Polio, 2007).

Most importantly, several studies have sought to pin down what encourages L2 learners to process, take-up and retain teacher written corrective feedback on writing, pointing to the impact of affective factors. F. Hyland (2003), for example, found that the extent her two case study students engaged with form-focused feedback varied greatly, so that one lower-intermediate student's response to teacher feedback was strongly influenced by her emotional reactions to the teachers' comments on her work. Storch and Wigglesworth (2010) similarly noted the importance of affective factors, with engagement among their case study students influenced by their attitudes, beliefs, and goals. They suggest that not only do affective factors affect the actions adopted by learners in responding to the feedback, they also have an impact on their willingness to accept and retain the feedback. The centrality of affect in student engagement is also highlighted by Lee and Schalert (2008) who argue that we need to rethink the cognitive process model of revision to give greater weight to the importance of establishing a trusting relationship between teacher and students.

Fredricks et al. (2004) tripartite conceptualisation of engagement has been picked up by Ellis' (2010) who suggests it can be applied to students' approaches to corrective feedback (CF). 
The extent learners attend to CF falls within the cognitive dimension; whether and how learners uptake the CF or revise their texts is seen as behavioral response, and learners' attitudinal response to the $\mathrm{CF}$ is their affective reaction. These three perspectives were also adopted by Han and Hyland (2015) in their study of four intermediate-level L2 students. These students cognitively processed teacher feedback by noticing and understanding linguistic errors as well as using cognitive strategies such as planning, prioritizing, monitoring, and evaluating. Behavioral engagement in included the use of implementing this cognition via revision strategies and use of external resources, while affective engagement referred to both positive and negative emotional responses.

These studies are provocative and inspirational, but almost all the previous research on student engagement looks at human feedback on writing, focuses on just one or two dimensions of engagement or is narrowly confined to error corrections. It is important to keep in mind that engagement is a multidimensional construct and student engagement with written feedback goes beyond error corrections.

With the emergence of computer-based educational technologies, research on L2 writing has expanded to include feedback provided by automated writing evaluation (AWE) systems. Supported by sophisticated technologies and statistical methods, these are able to analyze written texts at lexical, syntactic, and discursive levels, and offer automated scores. Looking at student responses to this feedback, Warden (2000) examined the redrafting time a group of $42 \mathrm{~L} 2$ students spent revising a draft after AWE feedback to determine the extent of time-on-task and therefore behavioral engagement. He found students spent an average of just six minutes on each draft. Grimes (2005) also found that students engaged only superficially with AWE feedback and identified a typical revision pattern whereby students submitted their first drafts, made a few 
corrections after receiving corrective feedback, and resubmitted their drafts as quickly as possible. Attali (2004) reported that over two thirds of the students in his study did not produce a second draft after receiving AWE feedback. Likewise, half of the students in El Ebyary and Windeatt's (2010) study never redrafted their essays after AWE feedback. A recent study by Zhang (2017) looks at an L2 student's behavioural, emotional and cognitive engagement with AWE feedback, but focuses on the impact of AWE on writing development rather than revision.

In a review of the effects of AWE feedback on student writing, Lai (2010) classified the research into three strands: (1) the effects on students' written products (e.g. scores, error rates, and text length); (2) the effects on students' writing processes (e.g. editing time, rates of revisions, and time on task); (3) perceived usefulness. The bulk of AWE feedback research, however, has focused on students' written products, with little attention paid to students' writing and revising process. As Stevenson and Phakiti (2014) have noted, students' behavioral engagement with AWE feedback (using AWE feedback to revise their drafts) tells us little about whether students have adopted cognitive and metacognitive strategies to notice, evaluate and finally improve their writing. Studies which examine how individual students engage with AWE feedback in their revising process are therefore urgently needed, and such studies need to reflect teaching and learning realities rather than experimental conditions (e.g. Qi \& Lapkin, 2001; Storch \& Wigglesworth, 2010).

Drawing on student engagement literature on both human and AWE feedback on L2 writing, we develop and strengthen Fredricks et al. (2004) model of student engagement and demonstrate its relevance for analysing L2 student responses to feedback on their writing. We see engagement as composed of three interlocking and overlapping dimensions: 
- Behavioral engagement refers to students' uptake to feedback such as time spent on revision tasks and revision actions (e.g. consulting dictionaries or peers)

- Affective engagement includes students' emotional responses (e.g. anxiety) and attitudinal reactions (e.g. dislike) to corrective feedback.

- Cognitive engagement is concerned with how students attend to the feedback. This embraces (1) understanding and interpreting, (2) evaluating and reflecting, (3) planning and revising, (4) monitoring and self-regulation

We can represent this diagrammatically and Figure 1 shows engagement as composed of overlapping elements and influenced by individual and contextual factors as students respond to teacher or AWE feedback.

\section{Figure 1. A model of student engagement with feedback on writing}

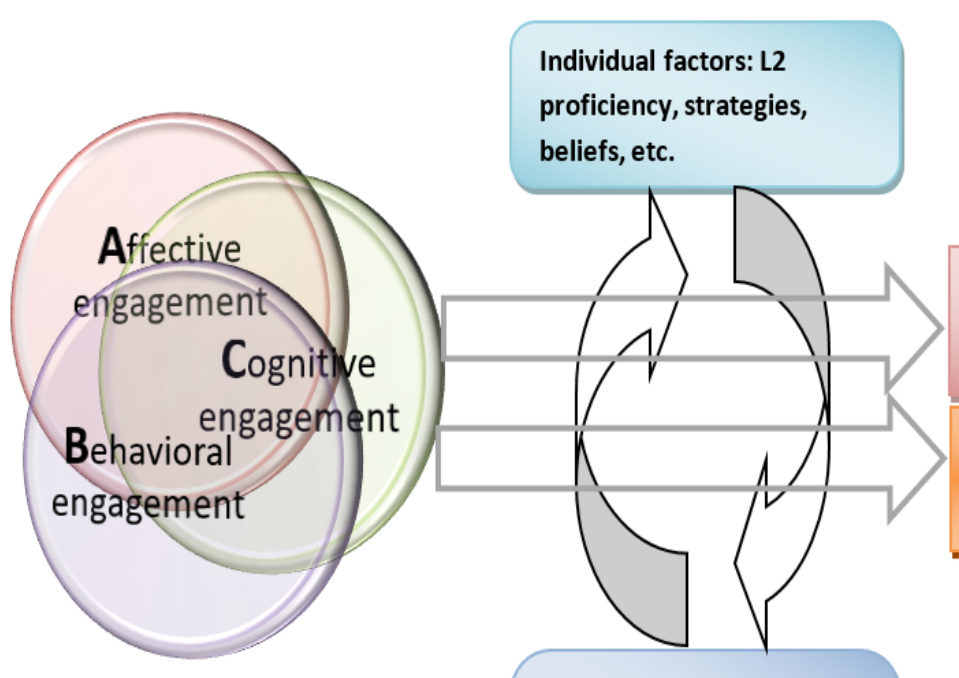

Teacher feedback

on student writing

Contextual factors:

institutional mechanism,

learning conditions,

relationships with teachers

and peers, etc.

AWE feedback on

student writing 
We are, then, interested in a gap in the research literature concerning how students engage with both teacher and AWE feedback on writing in an authentic context. In the study we set out to answer the following questions:

1. How does teacher feedabck differ from AWE feedbck?

2. How do L2 students engage with teacher feedback and AWE feedback on their English writing?

3. What factors might influence the student engagement with two types of feedback?

\section{Participants, context and methods}

The participants in this study were two Chinese students in the first semester of their third year in a university in China. They were shortlisted on the basis of their responses to a questionnaire on English writing completed by 206 students and selected partly for their typicality and partly because they were following the same course and enrolled in the same class. This allowed us to ensure the two participants had the same AWE assignments and would receive the same teaching and feedback from the same teacher. David, aged 22, is a male student majoring in English Education with an IELTS score of 5.5, which is the level of the majority of students in the cohort. Flora is a 21-year-old female student in the same class and while her IELTS score of 7.5 is atypical, we believed she would be an interesting case study as a result of the active engagement with feedback we had observed in the previous semester.

Data was collected from the two students during a 16-week semester in which they were enrolled in two EAP courses: Advanced English and Tourism English. Both courses were offered in a two-hour session once a week. In Advanced English, the two participants were given six weeks to finish one 400-word essay describing why they chose to attend this university and 
how it would help them achieve their academic goals. The teacher asked the students to submit their essay to an AWE system and make revisions based on the AWE feedback before the final submission to the teacher. The AWE system was Pigai (http://www.pigai.org/) which is managed by a Chinese company and used by tens of thousands of students in as many as 5,000 Chinese universities. The programme works in a similar way to AWE systems such as Criterion and MY Access in providing holistic scoring, a ranking, four-category descriptors, and end comments (see Appendix A) as well as corrective feedback (see Appendix B). It differs from these programmes in being free to users. Flora resubmitted her essay 13 times, while David made one resubmission.

The AWE system provided a rich source of data as it not only saved drafts and AWE feedback, but also recorded the submission time of each draft. In Tourism English, the course instructor did not require use of Pigai but assigned the students one 1,000-word essay introducing a city or country. This was assigned midway through the course and they were asked to submit their first draft in the eighth week to get teacher feedback before submitting their final draft in the $10^{\text {th }}$ week. The grading rubrics for both essays gave equal marks for the range and accuracy of vocabulary, grammar, paragraphing and structure, and 'task fulfilment' referring to the development of relevant ideas. In other words, there was considerable emphasis on language accuracy.

We collected students' drafts, AWE feedback and submission information in the AWE system, and teacher feedback on the draft for textual analysis. We also conducted two retrospective semi-structured interviews with each student: partway through the semester when the students had finished their first drafts and at the end after they had submitted their final drafts in both courses. Each interview lasted approximately one hour and was conducted in the 
participants' first language. Interviews were recorded, transcribed verbatim, and translated into English. In order to obtain a better understanding of the context, documents including syllabus, timetables, lesson plans, textbooks, and grading rubrics were also collected for analysis.

Having collected the written data we first identified all the teacher feedback points (F. Hyland, 1998) and coded them according to a modified version of Ferris's (2006) taxonomy. We then followed the same categorization scheme to code the AWE feedback. In addition to corrective feedback, the AWE feedback included three features which differed from the teacher feedback: praise, a number of high frequency phrases, and suggestions for further study. We categorized the feedback according to the focus (i.e. the type of error the feedback targeted) and the type (how the feedback was given). The former comprised 16 common grammatical errors (see Table 1) and the latter five types: highlighting (feedback that draws attention to errors both explicitly with words and implicitly with codes); direct correction (providing the correct answer); marginal comments, end comments; and grades (see Table 2). The revisions made by the students in response to teacher and AWE feedback were identified as revision operations. After recursive passes through the feedback and students' writing we classified revisions into seven categories: (1) correction, (2) no correction, (3) deletion, (4) substitution, (5) addition, (6) reorganization and (7) rewriting.

\section{Differences between teacher and AWE feedback}

Teacher feedback addressed more error types (16) than the AWE feedback (8), although differences in the two assignments may have influenced this, with factors such as difficulty and length causing students to commit different types of errors. However, a careful examination of the student texts showed that many mechanical errors such as number and abbreviations were not 
diagnosed by the AWE system. But while teacher feedback may have advantages in this area, AWE feedback tended to highlight, rather than correct, student errors. There is no consensus in the literature regarding the effectiveness of such indirect feedback on learning, this process can help raise students' awareness of their mistakes (Ferris, 2002). The comparisons between two types of feedback are presented in Table 1 and Table 2.

Table 1 Comparison of error focus between teacher feedback and AWE feedback

\begin{tabular}{|c|c|c|}
\hline Error focus & Teacher feedback & AWE feedback \\
\hline Spelling & $\checkmark$ & $\checkmark$ \\
\hline Noun & $\checkmark$ & $\checkmark$ \\
\hline Preposition & $\checkmark$ & \\
\hline Verb & $\checkmark$ & \\
\hline Article & $\checkmark$ & \\
\hline Pronoun & $\checkmark$ & $\checkmark$ \\
\hline Adjective & $\checkmark$ & $\checkmark$ \\
\hline Adverb & $\checkmark$ & \\
\hline Conjunction & $\checkmark$ & \\
\hline Abbreviation & $\checkmark$ & \\
\hline Capitalization & $\checkmark$ & \\
\hline Number & $\checkmark$ & \\
\hline Possessive & $\checkmark$ & \\
\hline Collocation & $\checkmark$ & \\
\hline Word choice & $\checkmark$ & \\
\hline Sentence & $\checkmark$ & \\
\hline Total & 16 & \\
\hline
\end{tabular}

Table 2 Comparison of feedback type between teacher feedback and AWE feedback

\begin{tabular}{|l|c|c|}
\hline Feedback type & Teacher feedback & AWE feedback \\
\hline Highlighting & $\checkmark$ & $\checkmark$ \\
\hline Correction & $\checkmark$ & \\
\hline Marginal comment & $\checkmark$ & $\checkmark$ \\
\hline End comment & $\checkmark$ & $\checkmark$ \\
\hline Grade & $\checkmark$ & $\checkmark$ \\
\hline
\end{tabular}


We now look at the engagement of the two students with their feedback in more detail.

\section{Flora: A highly engaged learner}

We characterise Flora as a student who demonstrated deep and full engagement with both teacher and AWE feedback on her writing. She took considerable time over her revisions, made numerous changes and submissions to the AWE and employed a repertoire of different stratagems: planning, goal-setting, monitoring, evaluating, and so on. Zimmerman (1989, p. 329) defines such learners as 'self-regulated' and argues that they "are metacognitively, motivationally, and behaviorally active participants in their own learning process". Flora certainly seemed to be motivated and willing to deploy a range of cognitive and metacognitive actions to learn. Table 3 shows the type and number of revision operations utilized by Flora in the two assignments.

Table 3 Revision operations in Flora's two assignments

\begin{tabular}{|l|c|c|}
\hline Revision operations & Responding to teacher feedback & Responding to AWE feedback \\
\hline Correction & $\checkmark$ & $\checkmark$ \\
\hline No correction & $\checkmark$ & $\checkmark$ \\
\hline Deletion & $\checkmark$ & $\checkmark$ \\
\hline Substitution & $\checkmark$ & $\checkmark$ \\
\hline Addition & $\checkmark$ & $\checkmark$ \\
\hline Reorganization & $\checkmark$ & $\checkmark$ \\
\hline Rewriting & $\checkmark$ & \\
\hline
\end{tabular}

\section{i) Engagement with teacher feedback}


A comparison between the second draft and the first draft of Flora's essay showed that she responded to teacher feedback by carrying out a variety of revision operations. She said in the interview that she spent considerable time in the revision process:

I spent a whole evening working on the second draft...I consulted an online dictionary and also checked with my classmates.

Flora also mentioned that she was very surprised about the amount of teacher feedback she received and how conscientious the teacher was, although she was embarrassed by the fact that some errors were due to her carelessness:

I was taken aback by the detailed teacher feedback in my essay. I never received so much teacher-written feedback in the past two years. ... The teacher pointed out all the article errors such as "a" and "the", and he provided corrected answers next to the wrong ones...Even punctuation and number usage... I was very grateful that the teacher was so responsible, but I felt ashamed of some silly mistakes.

Being used to perfunctory and generic teacher feedback over the previous two years meant Flora valued such a large amount of detailed teacher feedback. Her affective engagement also had a positive impact on her cognitive engagement with teacher feedback, as she told us in her interview:

I felt very motivated [by teacher feedback] to produce a better draft, so I put in a lot of efforts in the revision process.

Analysis of Flora's second draft showed that she employed seven revision operations: correction, no correction, deletion, substitution, addition, rewriting, and reorganization. Firstly, Flora effectively corrected all the linguistic errors explicitly identified by the teacher, but missed the one error which the teacher only implicitly indicated. She also addressed confusing parts of her essay by deleting unnecessary words and sentences, and adding more explanations to 
increase clarity. Redundant words and phrases that were either circled or underlined were substituted with more concise ones. Importantly, Flora cognitively engaged with the teacher feedback by rewriting and reorganizing some sentences and paragraphs. For example, in one paragraph the word "propaganda" was circled by the teacher, so Flora checked the usage and made changes in the original sentence. The changes also led her to rewrite the subsequent sentence (see Figure 2 -bolded text indicates additional material)

Figure 2. Example of rewriting in Flora's $2^{\text {nd }} d r a f t$

First draft: ... Last but not least, the cultural institution in Cairo should strengthen the propaganda of heritage protection to enhance the public's awareness of preserving cultural and natural heritage sites.
Second draft: ... Third, the cultural institution should enhance the public awareness of preserving cultural and natural heritage sites. Last but not least, in order to alleviate the conflict between the development of tourism industry and the environment, not only destination residents but also visitors should give full support to the sustainable tourism development in Cairo.

She explained why she rewrote these sentences in the interview:

I should have used "awareness" rather than "propaganda"... I was thinking about what public awareness refers to, and I decided to include both local residents and visitors.

The revision also showed evidence of organizational rearrangement, where Flora said she had split one of the paragraphs into two by adding a transitional sentence to "make the logical progression more smooth" (see Figure 3).

Figure 3. Example of reorganization in the $2^{\text {nd }} \mathrm{draft}$ 
First draft: Cairo has formed a relatively complete infrastructure, such as the medical treatment, the educational system and the more convenient transportation system like rail system, subway system, and maritime services.
Second draft: Thanks to the economic benefits created by the tourism industry, Cairo has developed a relatively complete infrastructure, such as hospitals, schools and a more convenient transportation system like rail

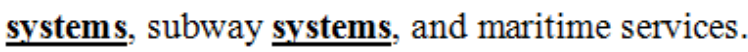

\section{ii) Engagement with AWE feedback}

Flora also demonstrated a similarly high level of engagement with AWE feedback on her essay. Figure 4, from the AWE record, shows that Flora resubmitted her essay 13 times, and the score rose from 79 to 90 (100 as the full score).

Figure 4. Screenshot of Flora's use of the AWE

\begin{tabular}{|c|c|c|}
\hline Draft & Time of submission & Score \\
\hline 版本 & 时间 & 成绩 \\
\hline 1 & $2014-10-2820: 23: 37$ & 79 \\
\hline 2 & $2014-10-2917: 54: 57$ & 86.5 \\
\hline 3 & $2014-10-2922: 50: 18$ & 87.5 \\
\hline 4 & $2014-10-2922: 52: 04$ & 88 \\
\hline 5 & $2014-11-0517: 35: 02$ & 87 \\
\hline 6 & $2014-11-0517: 36: 15$ & 88 \\
\hline 7 & $2014-11-0517: 36: 47$ & 88 \\
\hline 8 & $2014-11-0517: 38: 44$ & 88.5 \\
\hline 9 & $2014-11-0517: 39: 22$ & 88.5 \\
\hline 10 & $2014-11-0517: 40: 23$ & 88.5 \\
\hline 11 & $2014-11-0517: 41: 12$ & 89 \\
\hline 12 & $2014-11-0517: 43: 10$ & 89.5 \\
\hline 13 & $2014-11-0517: 43: 39$ & 89.5 \\
\hline 14 & $2014-11-0517: 46: 33$ & 90 \\
\hline
\end{tabular}


The high number of resubmissions to the programme show that Flora was fully engaged behaviorally with the revision task. The timestamp, moreover, shows that she wrote her revisions over two days with one-week between them, indicating some reflection about the process between submissions. When she got the AWE feedback on her first draft, Flora did not revise her draft immediately but started the following day, with a five-hour gap between her second and third submission. Together with her improved score, this indicated that Flora spent some time revising her essay and made efforts to improve the quality of her writing. In the interview, Flora described how she felt about the AWE feedback:

I felt very frustrated about the feedback and demoralized by the score, so I didn't revise my essay right away... When I calmed down the following day, I started to look at the feedback more rationally. I was happy to see that after addressing the errors the score increased by 9 points.

Flora's interaction with the AWE feedback clearly involved considerable emotional investment. Although it is often the case that students are score-obsessed, an increase in the score can also help motivate some students to improve their work. In Flora's case, she also mentioned that the improvement of the score served as a positive confirmation, telling her she was on the right track. In addition, she talked about how her perception of AWE feedback changed incrementally:

In the beginning I thought it was only generated automatically, so it was not smart enough compared to humans. However, when I was aware that there was a scoring rubric created by some developers in this system, I thought the feedback was valid and reliable... I can get feedback whenever I want, so I think it's very helpful.

In terms of cognitive engagement, Flora made use of cognitive and metacognitive strategies in the revision process. Her revision operations included correction, deletion, addition, 
substitution, reorganization, and rewriting. In her second draft, Flora successfully corrected most linguistic errors using the AWE feedback. She also substituted simplistic terms and phrases with more sophisticated ones. Most conspicuously, Flora rewrote her draft numerous times in the multiple-draft assignment, not only correcting errors but improving the style and explicitness of the text. The rewriting in Figure 5, for example, was in response to the AWE feedback on lexical and syntactic structures.

Figure 5. Example of Flora's rewriting in the AWE assignment

$1^{\text {st }}$ draft: ... With the sincere help of the senior students, I got accustomed to my college life...

$4^{\text {th }}$ draft: ... Thanks to the conditional help of the senior students, I got accustomed to my college life...

$7^{\text {th }}$ draft: ... Thanks to the selfless help and kind advice of the senior students, I got accustomed to my college life...

Flora explained why she made the changes and how she like the AWE feedback:

I did this because the comment said that I need to improve lexical range and sentence structures... I really like the multiple drafting opportunities when engaging with AWE feedback.

Central to cognitive strategies are self-monitoring and self-regulation, a willingness to invest time, effort and thought into revising processes and using one's judgement to reflect on and approve changes made to the text. Flora said that sometimes she really took her time to make revisions because she wanted to process the AWE feedback more thoroughly, especially the special features of the AWE feedback: confirmation and suggestions for further study. She wanted to control the time and the direction of the reading and writing process in making changes, as she said "I was not in a hurry... I needed to think carefully". 
Some errors noted by the AWE feedback Flora deliberately ignored, making no revisions at all. She did this intentionally to avoid being overwhelmed by the thinking and revising process. Instead, she wanted to focus on some problem areas before moving on to others.

Sometimes I paused for a while to make sure that I fully mastered a specific language point... I can't focus on too many areas at one time.

Overall, the pattern of Flora's revision operations suggests she was cognitively engaged with the AWE feedback. On one hand, she wanted to take control of her reading, writing, and revising process. In her mind, she understood that there was no need to rush the process, and it was very important to think carefully about how to make effective revisions. On the other hand, she was aware of her own learning style and tried to monitor the revision process by checking if she really internalized some important knowledge.

\section{David: A moderately engaged learner}

In contrast to Flora, David was far less-engaged in his approach to feedback and revision. His response to both sources of feedback was more passive, and demonstrated lower levels of self-starting and participation. He seemed less willing to reflect on the data provided to him on his writing or take the initiative to improve his work without the guidance or intervention of a teacher. Table 4 shows the type and number of revision operations David made on his two assignments.

Table 4 Revision operations in David's two assignments

\begin{tabular}{|l|c|c|}
\hline $\begin{array}{l}\text { Revisions } \\
\text { operations }\end{array}$ & $\begin{array}{l}\text { Responses to } \\
\text { teacher feedback }\end{array}$ & $\begin{array}{l}\text { Responses to } \\
\text { AWE feedback }\end{array}$ \\
\hline Correction & $\checkmark$ & $\checkmark$ \\
\hline
\end{tabular}




\begin{tabular}{|l|c|c|}
\hline No correction & $\checkmark$ & $\checkmark$ \\
\hline Deletion & $\checkmark$ & $\checkmark$ \\
\hline Substitution & $\checkmark$ & $\checkmark$ \\
\hline Addition & $\checkmark$ & $\checkmark$ \\
\hline Reorganization & & \\
\hline Rewriting & & \\
\hline
\end{tabular}

\section{i) Engagement with teacher feedback}

In the second draft of his Tourism English essay David corrected most of his errors as these were explicitly identified and corrected by the teacher. This kind of mechanical revising according to the answers provided by the teacher is simply copying and can be done automatically without deep engagement. Much of the more implicit feedback provided by the teacher, such as circling, underlining and question marks, however, elicited very little response. In the interview, David expressed his confusion over this feedback:

When I saw some circles, underlines, and question marks, I was actually bewildered. I didn't know what the teacher meant... I prefer to be told. I think the teacher should offer us more help on how to revise our essays.

So, behaviorally, David attempted to attend to the teacher feedback and made revisions but a close look at the second draft reveals that instead of directly addressing the problem areas circled and underlined, he simply deleted some of the offending text. Therefore, deletion was second most frequently used revision operation after correction. In the interview, David explained this strategy:

If I still don't know what to do after checking the dictionary or talking to my friends, I often remove it to reduce the number of errors. 


\section{ii) Engagement with AWE feedback}

We can see in the screenshot in Figure 6 that David only resubmitted his essay once after receiving AWE feedback and only spent less than 14 minutes on the task. David therefore showed a low level of behavioral engagement with AWE feedback. When comparing the two drafts, we also noticed that many errors diagnosed by the AWE system were not properly addressed. The negligible increase of the score shows his revision was not effective. 
Figure 6. Screenshot of David's submission information

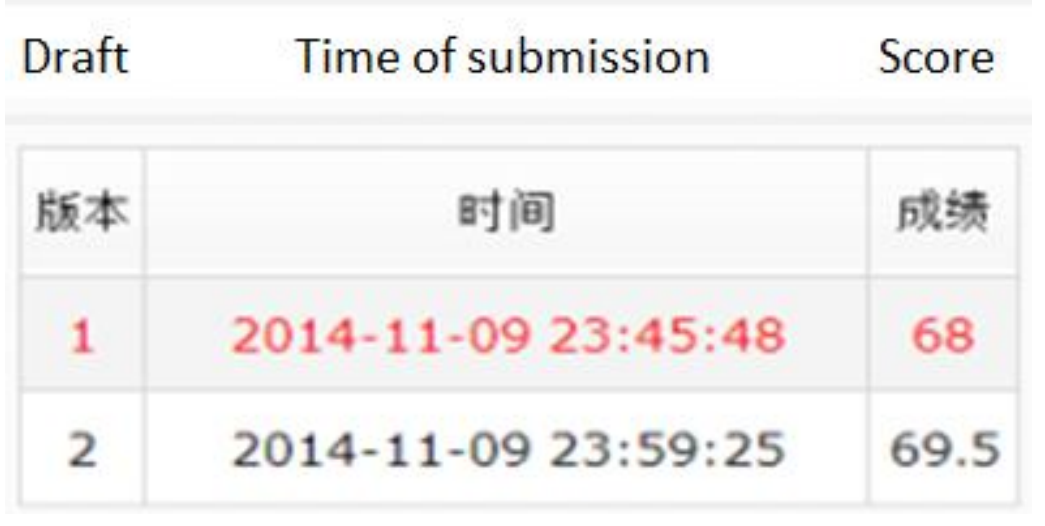

When asked how he felt about the AWE feedback on his essay, David said that he was overwhelmed by the amount of corrective feedback and felt helpless about how to address the problems. Affectively, the feedback created considerable anxiety for David and as a result he rejected its validity:

I was really shocked to see so many errors. It was just a little too much for me to take everything on board... But sometimes I'm not sure if the AWE feedback is reliable because it's just a machine.

David made 35 errors in seven categories: adjective, noun, verb, spelling, punctuation, collocation, and sentence structure. Given that it was only a 400-word essay, David made an error every 12 words in the first draft, which explains why he found the feedback overwhelming. More wounding was the score the AWE awarded him. He recalled how he felt when he saw the score of 69.5:

I felt very disappointed about the score. I never got a score below 70. It was so frustrating that I didn't feel able to go back to it again to change the essay.

To understand how David cognitively engaged with the AWE feedback we analyzed the revision operations he used. We found a very limited range of revision operations in the second draft and out of 35 errors seven were corrected properly. Five errors were deleted, one was 
substituted, one correction was added and 21 errors were not addressed. In all, the changes were minimal and he neither reorganized nor rewrote any part of his essay. To better understand his cognitive engagement with AWE feedback, we asked him to recall how he went about revising the draft after receiving the computer feedback:

I looked at online dictionaries and corrected some spelling errors and nouns from the feedback but I was not sure how to correct the others... I didn't ask my classmates for help because I felt embarrassed with the score.

Clearly the disappointment of the low score and the number of errors the programme found shook David's confidence and willingness to seek help. He also mentioned in the interview that the teacher did not advise the students how many times he expected them to revise their essays or the overall score he expected them to get. This lack of teacher support, in addition to the negative emotions created by his experience of the AWE score combined to discourage David from engaging either behaviorally or cognitively with the AWE feedback.

\section{Comparison between the two types of learners}

This detailed description of how the two learners engaged with both teacher and AWE feedback on their writing shows that the highly engaged learner (Flora) outperformed the moderately engaged learner (David) in her response to both sources of feedback as well as in making more improvements to her text. In other words, the student who was more motivated, proficient and adept at using learning strategies, Flora, demonstrated better engagement. But we believe it is not the mere possession of these qualities which leads to good responses to feedback, it is the active student engagement which produces an effective response.

We can see a willingness to respond to feedback and an ability to do so, not just in the abstract but in the forms of affective, behavioral, and cognitive engagement they employed with 
the two sources of feedback. Compared to David, Flora was more active in that she invested more time-on-task and more positive attitudes in the revision process. Her deep behavioral and affective engagement facilitated a more mindful engagement with both teacher and AWE feedback, making use of interpreting, planning, and evaluating skills to produce better drafts. The differences between their engagement types became more obvious in their responses to AWE feedback when there was a multiple drafting opportunity. Overall, we can see here a multidirectional interaction among the three types of engagement and a bi-directional interaction between the use of strategies and deep engagement.

\section{Factors influencing student engagement with feedback}

It is clear that the two students engaged with teacher and AWE feedback on their writing differently and we believe there were two main factors in this: the type of feedback the students received and individual learner traits.

\subsection{Feedback source}

Neither student was used to receiving detailed teacher feedback so they were often unsure about how to engage with it. In fact, if students are not supported with teacher feedback they tend to lack systematic revision skills (K Hyland, 2013). Institutional attitudes toward writing instruction and assessment can thus have a major impact on student engagement with feedback. The institution where the two students studied did not have a strong teaching and learning culture which attached importance to revision. The questionnaire data from 206 students showed that many students did not value teacher feedback, although the more highly motivated students claimed that they tried to engage with it and incorporate it into their drafts. 
More importantly, and central to the findings of this study, is that different feedback sources tend to elicit different engagement styles. This is particularly obvious in the case of the highly engaged learner. While learners can engage deeply with both teacher and AWE feedback by producing multiple drafts, we found that Flora enjoyed more autonomy when she responded to AWE feedback. This allowed her to regulate her revising time and the pace of her rewriting according to her own learning plan. For example, she revised one part of her writing and submitted it for a quick diagnose from the AWE and then worked on other parts of her text. In contrast, teacher feedback did not allow the same kind of flexibility and the absence of immediate feedback created greater uncertainty then the learners came to correct errors and rewrite their texts.

We also found that the two learners tended to differ between these sources in terms of their affective engagement. Flora evinced a strong emotional reaction to the feedback from both sources, as the teacher feedback elicited admiration for the teacher's assistance as well as some same about the errors she had made, encouraging revision. She also responded affectively to the more neutral delivered commentary of the AWE programme and the upgraded scores on her drafts, each gain encouraging her to improve further. David, however, did not engage affectively with either source to any extent. While more facilitative and less directive than the teacher feedback, he felt embarrassed and demoralised by the low score he received from the AWE and this discouraged his full engagement with it.

\subsection{Learner factors}

A number of learner factors are also likely to have influenced their responses to feedback and indicate the degree of engagement they were prepared, or able, to invest. Perhaps the most 
significant of these was language proficiency, which is related to cognitive engagement. We saw that David, with limited proficiency, had more difficulty understanding both teacher and AWE feedback than Flora. He was overwhelmed by the errors identified in his work and discouraged by his inability to respond to all but the most explicitly corrected of them. His lack of linguistic knowledge therefore impacted on his ability to correct errors and discouraged him from doing so, thus his cognitive, behavioural and affective engagement was reduced. Flora, in contrast, is a higher proficiency student and had relatively little difficulty interpreting both teacher and AWE feedback on her work. Although she turned to the same online dictionary as David to improve her writing, she went beyond this by seeking to diagnose what was incorrect. Her greater proficiency allowed her to thoroughly process both teacher and AWE comments, and use these to make effective revisions. Her proficiency thus enabled her to cognitively engage and encouraged her motivation (affect) and successful revisions (behavioural).

The ability to engage with feedback on writing, therefore, is not only determined by language ability as it also requires the motivation and interest to invest time and energy in the process as well as a repertoire of effective revision and writing operations to carry it out. These students varied in the techniques they were able to deploy, a factor related to their behavioural and cognitive engagement with feedback. David was less adept at revising to effectively respond to both sources of feedback, failing to correct the grammatical errors noted by the AWE feedback, for example, and so was demotivated to work on the second draft. While David's behavioral and cognitive engagement with AWE feedback was less limited, Flora's greater repertoire of learning strategies enabled her to interpret and use both teacher and AWE feedback, making better use of the online dictionary, for instance, to identify and correct errors. Overall, 
the cognitive and metacognitive strategies she used, such as making associations, planning, evaluating, and regulating of emotions, facilitated her engagement with two types of feedback.

As a highly engaged learner, Flora gravitated more towards "goal-oriented learning" rather than "performance-oriented learning", seeking to improve her skills and acquire knowledge rather than simply avoid making mistakes. This belief prompted her to actively use both cognitive strategies (e.g. monitoring and synthesizing) and affective strategies (e.g. adjusting emotions and using motivation) to improve both her draft and her writing skills. In contrast, David, responded mechanically to both teacher and AWE feedback, with a preference for spoonfeeding and a sceptical attitude to automated feedback. Affectively he was particularly disengaged with the AWE feedback, rejecting it as "only a machine". Thus instead of capitalizing on the advantages of computer-assisted language learning he was more concerned about its drawbacks, thus influencing the way he engaged with the AWE feedback.

\section{A comparison of teacher and AWE feedback}

While we have not sought to dichotomize these two sources of feedback, it is useful to consider what they have to offer in the formative assessment in L2 writing. AWE feedback has discernible advantages over teacher feedback in terms of timeliness, convenience, multiple drafting, and even potential learner autonomy, which have also been shown in the previous studies (Chen \& Cheng, 2008; Dikli, 2006). Learners seem eager to receive immediate feedback on their writing and engage in the revision process when the task is still fresh in their memory (K. Hyland, 2013). We have seen here that the opportunity to revise an essay multiple times at the learner's own pace is also an advantage of AWE feedback (cf Warschauer \& Ware, 2006). Learners can be empowered with the responsibility to revise their essays according to their own 
schedule, enjoying the autonomy offered by AWE feedback and, by capitalizing on the multiple drafting and revision opportunities to improve their drafts, can internalize language points in the revision process.

In sum, AWE feedback is a useful source of formative assessment in that it offers frequent and process-oriented diagnostic assessment in the revision process in which learners' active role is also emphasized. It therefore has the potential to activate learner engagement.

However, teacher feedback also has advantages. Most importantly, teachers' comments on content and organization are highly valued by student writers, partly because they are a human response to their writing and not a pattern-matching algorithm designed to highlight errors. Moreover, this study shows that experienced ESL teachers can offer more comprehensive corrective feedback on student writing, giving feedback on such issues as number usage and abbreviation which tend to be outside the scope of AWE feedback routines. Where teachers have large classes and heavy teaching loads, however, is vitally important for students to maximize their learning opportunities through effectively engaging with limited amounts of teacher feedback and to recognize the pedagogical potential of AWE feedback.

The examination of two types of feedback on L2 student writing indicates that it might be more effective to integrate the two types of feedback in classroom contexts. With the help of AWE feedback, teachers can adjust their feedback focus and allocate more time to instruction or to formative assessment aimed at the rhetorical development of student drafts. Thus, future research might explore the integration of both teacher and AWE feedback in the same writing assignment. Overall, however, the type of feedback received, whether human or machine sourced, is likely to influence individual learner engagement in revision, and a better 
understanding of how students engage with teacher and AWE feedback differently may help us make better-informed decisions regarding the sources of feedback we offer our students.

\section{Conclusions}

This study has focused on how two individual students engaged with teacher and AWE feedback on their writing during a university semester and offers some insights into the complex processes of learner engagement with writing tasks. Such engagement is a dynamic process whereby behavioral, affective, and cognitive responses are simultaneously at work.

The different styles of engagement adopted by these students led us to identify one as a highly engaged learner and the other as a moderately engaged learner, and this helped us to see how each responded to teacher and AWE feedback differently. Both students displayed behavioral engagement with two types of feedback on their writing although the depth of this varied. The highly engaged learner tended to participate actively and reflect more deeply with both teacher and AWE feedback on her writing, while the moderately engaged learner was less motivated and showed less willingness to use the feedback he received from both sources. More highly engaged learners thus tend to spend more time working with feedback, show more positive attitudes toward it, and employ more revising strategies, demonstrating that behavioral, affective, and cognitive engagement dynamically interact with each other.

We hope to have shown that student engagement with feedback is a key construct in L2 writing research that merits more attention. Both the source of the feedback and individual learner factors can shape the process so that language proficiency and knowledge of learning strategies can play a pivotal role, not only in helping students to understand and interpret feedback, but also in evaluating and monitoring the revision process. Affective factors such as 
reactions to red ink or a sympathetic tone, and student learning beliefs also have a profound influence on how they engage with the two types of feedback. These observations remind us that L2 teachers can play a key role in helping students to establish positive attitudes to learning and in making good use of feedback. Here explicit instruction on the use of cognitive strategies, adopting a reassuring tone and employing classroom practices which enhance language proficiency can be crucial.

\section{References}

Appleton, J. J., Christenson, S. L., Kim, D., \& Reschly, A. L. (2006). Measuring Cognitive and Psychological Engagement: Validation of the Student Engagement Instrument. Journal of School Psychology, 44(5), 427-445. doi: 10.1016/j.jsp.2006.04.002

Attali, Y. (2004). Exploring the feedback and revision features of Criterion. Paper presented at the National Council on Measurement in Education (NCME), San Diego, CA.

Boekaerts, M., Pintrich, P. R., \& Zeider, M. (1999). Handbook of Self-Regulation: United States: Academic Press.

Carless, D. (2006). Differing perceptions in the feedback process. 31(2), 219-233. doi: 10.1080/03075070600572132

Chen, C.-F. E., \& Cheng, W.-Y. E. (2008). Beyond the Design of Automated Writing Evaluation: Pedagogical Practices and Perceived Learning Effectiveness in EFL Writing Classes. Language Learning \& Technology, 12(2), 94-112.

Dikli, S. (2006). An overview of automated scoring of essays. Journal of Technology, Learning, and Assessment, 5(1), 1-35.

El Ebyary, K., \& Windeatt, S. (2010). The Impact of Computer-Based Feedback on Students' Written Work. International Journal of English Studies (IJES), 10(2), 121-142.

Ellis, R. (2010). EPILOGUE. Studies in Second Language Acquisition, 32(2), 335-349. doi: $10.1017 /$ S0272263109990544

Ferris, D. (1997). The Influence of Teacher Commentary on Student Revision. TESOL Quarterly, 31(2), 315-339. doi: 10.2307/3588049

Ferris, D. (2002). Treatment of error in second language student writing. Ann Arbor: Ann Arbor : University of Michigan Press.

Ferris, D. (2006). Does error feedback help student writers? New evidence on the short- and long-term effects of written error correction. In K. Hyland \& F. Hyland (Eds.), Feedback in second language writing: Contexts and issues (pp. 81-104). New York: Cambridge University Press

Finn, J. D. (1989). Withdrawing from School. Review of Educational Research, 59(2), 117-142. doi: 10.3102/00346543059002117

Fredricks, J. (2013). Behavior engagement in learning. In J. Hattie \& E. M. Anderman (Eds.), International guide to student achievement (pp. 42-44). New York, NY: Routledge. 
Fredricks, J., Blumenfeld, P. C., \& Paris, A. (2004). School engagement: Potential of the concept, state of the evidence Rev. Educ. Res. (Vol. 74, pp. 59-109).

Fredricks, J., \& McColskey, W. (2012). The measurement of student engagement: A comparative analysis of various methods and student self-report instruments. In S. L. Christenson, A. L. Reschly \& C. Wylie (Eds.), Handbook of research on student engagement (pp. 763-782). New York, NY: Springer.

Gamoran, A., \& Nystrand, M. (1992). Taking students seriously. In F. Newmann (Ed.), Student engagement and achievement in American secondary schools (pp. 40-61). New York: Teachers College Press.

Goldstein, L. M. (2005). Teacher written commentary in second language writing classrooms. Ann Arbor: Ann Arbor : University of Michigan Press.

Grimes, D. (2005). Assessing automated assessment: Essay evaluation software in the classroom. Paper presented at the Computers and Writing Conference, Stanford, CA.

Han, Y., \& Hyland, F. (2015). Exploring learner engagement with written corrective feedback in a Chinese tertiary EFL classroom. Journal of Second Language Writing, 30, 31. doi: 10.1016/j.jslw.2015.08.002

Handley, K., Price, M., \& Millar, J. (2011). Beyond 'doing time': investigating the concept of student engagement with feedback. Oxford Review of Education, 37(4), 543-560. doi: 10.1080/03054985.2011.604951

Hyland, F. (1998). The impact of teacher written feedback on individual writers. 7(3), 255-286.

Hyland, F. (2003). Focusing on form: Student engagement with teacher feedback. 31(2), 217230.

Hyland, K. (2013). Faculty Feedback: Perceptions and Practices in L2 Disciplinary Writing. Journal of Second Language Writing, 22(3), 240-253. doi: 10.1016/j.jslw.2013.03.003

Hyland, K. (2016). Teaching and researching writing: New York, NY : Routledge.

Lai, Y. H. (2010). Which do students prefer to evaluate their essays: Peers or computer program. British Journal of Educational Technology, 41(3), 432-454. doi: 10.1111/j.14678535.2009.00959.x

Mendonca, C. O., \& Johnson, K. E. (1994). Peer Review Negotiations: Revision Activities in ESL Writing Instruction. Tesol Quarterly, 28(4), 745-769.

Perry, N. E., Turner, J. C., \& Meyer, D. K. (2006). Classrooms as contexts for motivating learning. In P. A. Alexander \& P. H. Winne (Eds.), Handbook of educational psychology (2nd ed., pp. 327-348). Mahwah, NJ: Lawrence Erlbaum.

Pessoa, L. (2008). On the relationship between emotion and cognition. Nature Reviews Neuroscience, 9, 148-158.

Price, M., Handley, K., \& Millar, J. (2011). Feedback: focusing attention on engagement. Studies in Higher Education, 36(8), 879-896. doi: 10.1080/03075079.2010.483513

Qi, D. S., \& Lapkin, S. (2001). Exploring the Role of Noticing in a Three-Stage Second Language Writing Task. Journal of Second Language Writing, 10(4), 277-303. doi: 10.1016/S1060-3743(01)00046-7

Skinner, E. A., \& Belmont, M. J. (1993). Motivation in the Classroom: Reciprocal Effects of Teacher Behavior and Student Engagement Across the School Year. Journal of Educational Psychology, 85(4), 571-581. doi: 10.1037/0022-0663.85.4.571

Skinner, E. A., Kindermann, T. A., \& Furrer, C. J. (2009). A Motivational Perspective on Engagement and Disaffection: Conceptualization and Assessment of Children's Behavioral and Emotional Participation in Academic Activities in the Classroom. 

$10.1177 / 0013164408323233$

Skinner, E. A., \& Pitzer, J. R. (2012). Developmental dynamics of student engagement, coping, and everyday resilience. In S. L. Christenson, A. L. Reschly \& C. Wylie (Eds.), Handbook of research on student engagement (pp. 21-44). New York, NY: Springer.

Stevenson, M., \& Phakiti, A. (2014). The effects of computer-generated feedback on the quality of writing. Assessing Writing, 19, 51-65. doi: 10.1016/j.asw.2013.11.007

Stipek, D. (2002). Good instruction is motivating. In A. Wigfield \& J. Eccles (Eds.), Development of achievement motivation (pp. 309-332). San Diego, CA: Academic Press.

Storch, N., \& Wigglesworth, G. (2010). Learners' Processing, Uptake, and Retention of Corrective Feedback on Writing. Studies in Second Language Acquisition, 32(2), 303334. doi: 10.1017/S0272263109990532

Truscott, J., \& Hsu, A. Y.-p. (2008). Error Correction, Revision, and Learning. Journal of Second Language Writing, 17(4), 292-305. doi: 10.1016/j.jslw.2008.05.003

Voelkl, K. E. (1997). Identification with School. American Journal of Education, 105(3), 294318. doi: $10.1086 / 444158$

Warden, C. A. (2000). EFL Business Writing Behaviors in Differing Feedback Environments. Language Learning, 50(4), 573-616. doi: 10.1111/0023-8333.00141

Warschauer, M., \& Ware, P. (2006). Automated Writing Evaluation: Defining the Classroom Research Agenda. Language Teaching Research, 10(2), 157-180. doi: 10.1191/1362168806lr190oa

Weissberg, R. (2006). Conversations about writing: Building oral scaffolds with advanced L2 writers. In K. Hyland \& F. Hyland (Eds.), Feedback in second language writing: Contexts and issues. . New York: Cambridge University Press.

Willms, J. (2003). Student engagement at school a sense of belonging and participation results from PISA 2000. Paris: OECD.

Zhang, Z. (2017). Student engagement with computer-generated feedback: a case study. ELT Journal, 71(3), 317-328.

Zimmerman, B. J. (1989). A Social Cognitive View of Self-Regulated Academic Learning. Journal of Educational Psychology, 81(3), 329-339. doi: 10.1037/0022-0663.81.3.329

Zyngier, D. (2008). (Re)conceptualising Student Engagement: Doing Education Not Doing Time. Teaching and Teacher Education: An International Journal of Research and Studies, 24(7), 1765-1776. doi: 10.1016/j.tate.2007.09.004 


\section{Appendix A. AWE marking scheme and end comment on student text}

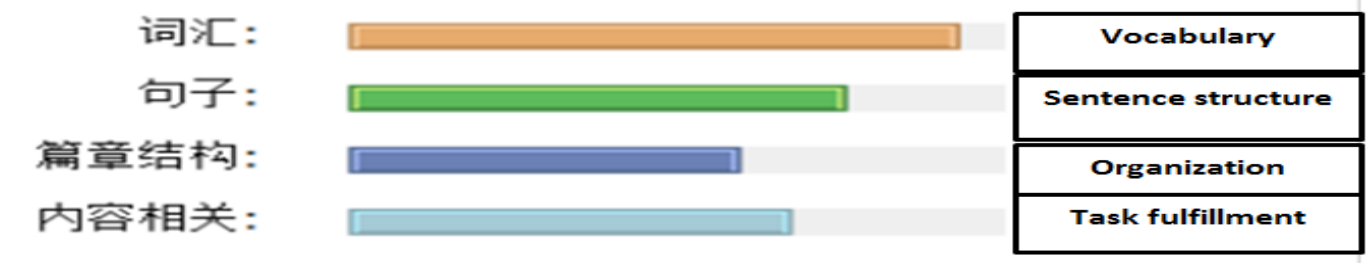

评语：从句使用墨不足，应增加从句和复合句的使

用; 作者高级词汇使用比较准确, 词汇表达较丰富, 但 仍需增加词汇积累; 上下文衔接不自然。

Comments: There is a limited range of sentence structures, so more clauses and complex sentences need to be used. The majority of advanced vocabulary is error-free. There is an adequate range of vocabulary, but more variety and flexibility need to be further improved. The information and ideas are not arranged coherently, and there is a lack of clear overall progression.

\section{Appendix B. AWE feedback on student text}

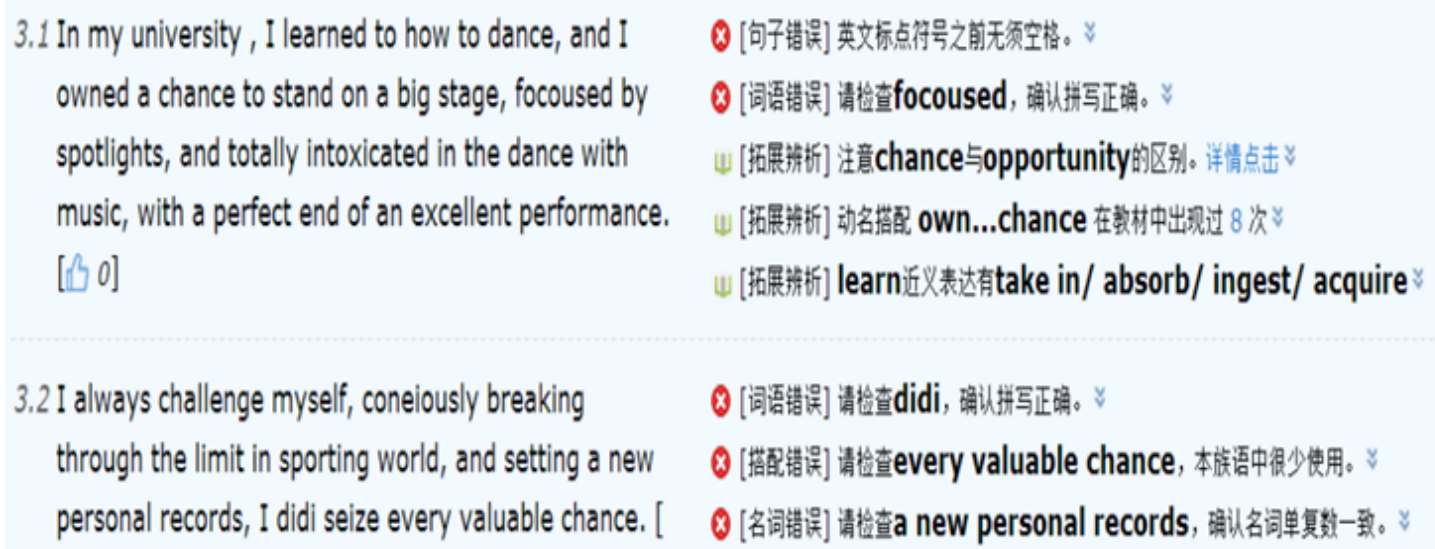


Table 1 Comparison of error focus between teacher feedback and AWE feedback

\begin{tabular}{|c|c|c|}
\hline Error focus & Teacher feedback & AWE feedback \\
\hline Spelling & $\checkmark$ & $\checkmark$ \\
\hline Noun & $\checkmark$ & $\checkmark$ \\
\hline Preposition & $\checkmark$ & \\
\hline Verb & $\checkmark$ & $\checkmark$ \\
\hline Article & $\checkmark$ & \\
\hline Pronoun & $\checkmark$ & \\
\hline Adjective & $\checkmark$ & $\checkmark$ \\
\hline Adverb & $\checkmark$ & $\checkmark$ \\
\hline Conjunction & $\checkmark$ & \\
\hline Abbreviation & $\checkmark$ & \\
\hline Capitalization & $\checkmark$ & $\checkmark$ \\
\hline Number & $\checkmark$ & \\
\hline Possessive & $\checkmark$ & \\
\hline Collocation & $\checkmark$ & $\checkmark$ \\
\hline Word choice & $\checkmark$ & \\
\hline Sentence & $\checkmark$ & $\checkmark$ \\
\hline Total & 16 & 8 \\
\hline
\end{tabular}


Table 2 Comparison of feedback type between teacher feedback and AWE feedback

\begin{tabular}{|l|c|c|}
\hline Feedback type & Teacher feedback & AWE feedback \\
\hline Highlighting & $\checkmark$ & $\checkmark$ \\
\hline Correction & $\checkmark$ & \\
\hline Marginal comment & $\checkmark$ & $\checkmark$ \\
\hline End comment & $\checkmark$ & $\checkmark$ \\
\hline Grade & $\checkmark$ & $\checkmark$ \\
\hline
\end{tabular}

Table 3 Revision operations in Flora's two assignments

\begin{tabular}{|l|c|c|}
\hline Revision operations & Responding to teacher feedback & Responding to AWE feedback \\
\hline Correction & $\checkmark$ & $\checkmark$ \\
\hline No correction & $\checkmark$ & $\checkmark$ \\
\hline Deletion & $\checkmark$ & $\checkmark$ \\
\hline Substitution & $\checkmark$ & $\checkmark$ \\
\hline Addition & $\checkmark$ & $\checkmark$ \\
\hline Reorganization & $\checkmark$ & $\checkmark$ \\
\hline Rewriting & $\checkmark$ & \\
\hline
\end{tabular}


Table 4 Revision operations in David's two assignments

\begin{tabular}{|l|c|c|}
\hline Revisions operations & Responding to teacher feedback & Responding to AWE feedback \\
\hline Correction & $\checkmark$ & $\checkmark$ \\
\hline No correction & $\checkmark$ & $\checkmark$ \\
\hline Deletion & $\checkmark$ & $\checkmark$ \\
\hline Substitution & $\checkmark$ & $\checkmark$ \\
\hline Addition & $\checkmark$ & $\checkmark$ \\
\hline Reorganization & & \\
\hline Rewriting & & \\
\hline
\end{tabular}


Figure 1. A model of student engagement with feedback on writing

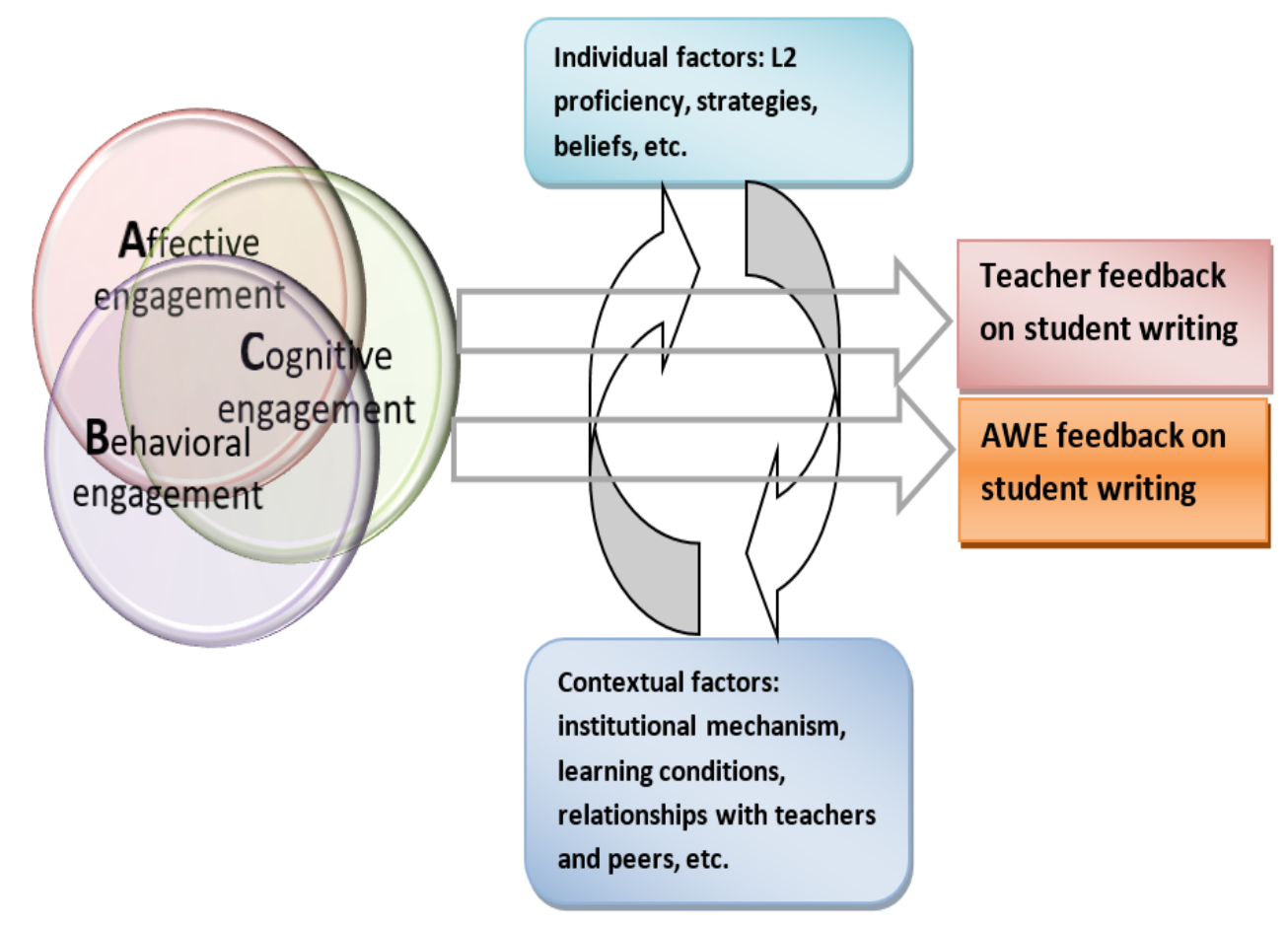

\section{Figure 2. Example of rewriting in Flora's $2^{\text {nd }}$ draft}

First draft: ... Last but not least, the cultural institution in Cairo should strengthen the propaganda of heritage protection to enhance the public's awareness of preserving cultural and natural heritage sites.
Second draft: ... Third, the cultural institution should enhance the public awareness of preserving cultural and natural heritage sites. Last but not least, in order to alleviate the conflict between the development of tourism industry and the environment, not only destination residents but also visitors should give full support to the sustainable tourism development in Cairo. 
Figure 3. Example of reorganization in the $2^{\text {nd }}$ draft

First draft: Cairo has formed a relatively
complete infrastructure, such as the medical
treatment, the educational system and the more
convenient transportation system like rail system,
subway system, and maritime services.

Second draft: Thanks to the economic benefits created by the tourism industry, Cairo has developed a relatively complete infrastructure, such as hospitals, schools and $\underline{\text { a more }}$ convenient transportation system like rail

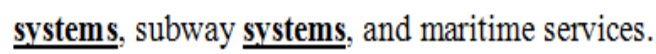

Figure 4. Screenshot of Flora's use of the AWE

\begin{tabular}{cc|c}
\hline Draft & Time of submission & Score \\
\hline 版本 & 时间 & 成绩 \\
\hline 1 & $2014-10-28$ 20:23:37 & 79 \\
\hline 2 & $2014-10-2917: 54: 57$ & 86.5 \\
\hline 3 & $2014-10-2922: 50: 18$ & 87.5 \\
\hline 4 & $2014-10-2922: 52: 04$ & 88 \\
\hline 5 & $2014-11-0517: 35: 02$ & 87 \\
\hline 6 & $2014-11-0517: 36: 15$ & 88 \\
\hline 7 & $2014-11-0517: 36: 47$ & 88 \\
\hline 8 & $2014-11-0517: 38: 44$ & 88.5 \\
\hline 9 & $2014-11-0517: 39: 22$ & 88.5 \\
\hline 10 & $2014-11-0517: 40: 23$ & 88.5 \\
\hline 11 & $2014-11-0517: 41: 12$ & 89 \\
\hline 12 & $2014-11-0517: 43: 10$ & 89.5 \\
\hline 13 & $2014-11-0517: 43: 39$ & 89.5 \\
\hline 14 & $2014-11-0517: 46: 33$ & 90 \\
\hline
\end{tabular}

Figure 5. Example of Flora's rewriting in the AWE assignment 
$1^{\text {st }}$ draft: ...With the sincere help of the senior students, I got accustomed to my college life...

$4^{\text {th }}$ draft: ... Thanks to the conditional help of the senior students, I got accustomed to my college life...

$7^{\text {th }}$ draft: ... Thanks to the selfless help and kind advice of the senior students, I got accustomed to my college life...

Figure 6. Screenshot of David's submission information

\begin{tabular}{|c|c|c|}
\hline Draft & Time of submission & Score \\
\hline 版本 & 时间 & 成绩 \\
\hline 1 & $2014-11-09$ 23:45:48 & 68 \\
\hline 2 & $2014-11-09$ 23:59:25 & 69.5 \\
\hline
\end{tabular}

